\title{
Neural Investigation of Human Trust Using Electroencephalogram
}

\author{
Seeung $\mathrm{Oh}^{1}$, Younho Seong ${ }^{2}$ \\ Applied Engineering Technology Department, North Carolina A \& T State University, Greensboro, NC 27411, USA ${ }^{1}$ \\ Industrial and Systems Engineering Department, North Carolina A \& T State University, Greensboro, NC 27411, USA ${ }^{2}$
}

\begin{abstract}
In contemporary society, workplaces have become more complex and dynamic because of the strong need to perform sophisticated tasks and use advanced technology. In these situations, trust can be an important factor of "decision aid" in dynamic and uncertain situations when complex systems are impossible to comprehend and when flexible behaviors are necessary to combat unexpected situations that arise, which are unavoidable. Measuring the human trust of a worker interacting with systems is vital in predicting his or her decision-making. This research examined human trust using an Electro Encephalo Gram (EEG) by recording, identifying and analyzing specific brainwaves. This research adopted a word elicitation study from previous research to evoke situations of trust and mistrust and used a power spectrum analysis for the recorded brainwaves. The results identified that while alpha and beta waves were stronger in the trust situations, gamma waves were stronger in the mistrust situations. Therefore, based on the activities of the brain waves associated with trust, we concluded that trust can impact effective decision-making by increasing concentration and performance, which are related to alpha and beta waves. Contrarily, mistrust can interrupt effective decision-making by increasing stress and anxiety, which are related to beta waves.
\end{abstract}

Keywords: Trust, Mistrust, Brainwaves, Electroencephalogram

\section{INTRODUCTION}

The word trust originated with trost, which means comfort in German. If I trust someone, it means that I am comforted by the belief that he or she will not do any action contrary to my expectation. Many researchers have proposed to define trust between humans related to expectation. Deutsch [1] defined trust as "confidence that one will find what is desired from another rather than what is feared." Scanzoni [2] claimed trust as "an actor's willingness to arrange and repose his or her activities on others because of the confidence that others will provide expected gratification." Rotter [3] defined the concept of interpersonal trust as "a generalized expectancy held by an individual that the world promise, oral or written statement of another individual or group can be relied on." Rempel et al. [4] explained trust as "a generalized expectation related to the subjective probability of an individual assign to the occurrence of some set of future events," and later, Rempel and Holmes [5] defined trust as "the degree of confidence one feels when thinking about a relationship." Barber [6] understood the multidimensional concept of trust and defined trust with three expectations of "the persistence of the natural and the moral social orders, technically competent role performance, and fiduciary obligations and responsibilities." Based on the definitions of trust by Barber [6] and Rempel and Holmes [5], Muir [7] defined trust in the human-machine relationship as such: "Trust is the expectation, held by a member of a system, of persistence of the natural and moral social orders, and of technically competence performance, and of fiduciary responsibility, from a member of the system, and is related to, but not necessarily isomorphic with, objective measures of these qualities." Therefore, it is necessary to understand trust as a multidimensional concept $[8,9]$. Trust is highly related to the idea of social influence because it would be much easier to influence or persuade someone who is trusting. Trust can also have a positive influence on a person's behaviors, perceptions and performances. Trust can predict the acceptance of behaviors by other individuals, social groups such as friends, communities, organizations, companies, nations and objects such as machines and automated systems [10]. Trust can play the important role of "decision aid" in dynamic and uncertain situations when complex automated systems are impossible to comprehend and when flexible behaviors are necessary to combat unexpected situations that arise, which are unavoidable [11].

How can we measure human trust effectively? Because trust is a multidimensional concept, measuring a worker's level of trust becomes crucial in predicting his or her decision-making while using the systems. Many researchers have used questionnaires that measure subjective feelings of trust $[4,12,13,14]$. However, the questionnaires used in these studies are based on a theoretical approach, which can vary by the researcher's theoretical orientation. Lee and Moray [13] used an experimental system, such as a semi-automatic pasteurization plant, that posed limitations when being applied to other automated systems due to the systems having different tasks or levels of complexity. Because trust is a multidimensional concept, we needed to use both quantitative and qualitative methods to measure trust. As a method 


\section{International Advanced Research Journal in Science, Engineering and Technology}

Vol. 6, Issue 7, July 2019

for this research, we used both a neurological imaging technique as a quantitative method and a questionnaire as a qualitative method to measure human trust. Neurological imaging techniques can measure quantitative aspects of trust by investigating relations between neurological activities and human trust. Up to now, there have been some studies investigating trust and neural correspondence [15,16,17]. Winston et al. [15] investigated the correlation between the degree of trust and human facial appearance using Event-Related Functional Magnetic Resonance Imaging (efMRI). Krueger et al. [16] examined interpersonal trust in an online context to detect different brain regions based on conditional and unconditional trust using hyper-fMRI. Another study defined a relationship between brain areas and psychological processes using fMRI that revealed a correlation between trust and mistrust with different brain areas [18]. These studies focused on brain regions using fMRI and efMRI that engaged with stimuli related to trust and mistrust. However, the previous studies did not fully investigate to identify specific brainwaves in the situations of trust and mistrust.

The aim of this research is to understand human trust by measuring and analyzing human brainwaves captured with an electroencephalogram (EEG). The experiment consisted of a word-elicitation study used to identify specific brainwaves (i.e., delta, theta, alpha, beta and gamma) which can aid in understanding brain activities relative to trust and mistrust.

\section{METHODOLOGY}

\section{A. Participants}

A total of 17 participants (male and female) were solicited to participate in the experiment. All participants would encompass undergraduate and graduate students recruited on campus at North Carolina A\&T State University. Each participant was over 18 years old, with normal or corrected-to-normal vision, was free of current or past neurological and psychiatric disorders and was able to read and comprehend the English language. There would be no preference on right-handed or left-handed users, but all participants must have the ability to use a keyboard and a mouse with their hands. There would be no discrimination upon participants based on age, race, gender, religion or prior participation in other experiments. Each participant was in an isolated room under guided instruction. Conditions for all participants were same.

\section{B. Framework for Experimentation}

This study adopted the framework from a previous study [19] containing words related to trust and mistrust that the survey participants ranked. This study utilized only the first through the $15^{\text {th }}$ ranked words (see Table I) relative to trust and mistrust $[19,20]$. The participants were expected to think about situations of trust and mistrust evoked by the words selected. After the participants were fitted with a cap of electrodes, they sat in front of the computer screen. Before the experiment began, the screen displayed instructions for 10 seconds. Words were displayed for 7 seconds/word, which is enough time to read the word and understand its meaning. Each slideshow display lasted for 3 minutes and 30 seconds, which is enough time to evoke a situation of trust or mistrust. Each experiment consisted of two sessions: 1) trust words and 2) mistrust words. The first session consisted of a slideshow of 30 random stimuli of the 15 words selected related to trust. The EEG recorded the participants' brainwaves. After the first session, the participants took a 1-minute break to avoid fatigue and stress. Similarly, the second slideshow consisted of 30 random stimuli of the 15 words selected related to mistrust. The EEG recorded the participants' brainwaves for mistrust. After the experiment, the participants completed a survey to evaluate the level of trust for trust and mistrust word sessions (see Fig. 1).

Table I Wordlists of trust and mistrust

\begin{tabular}{|l|l|l|}
\hline & Words related to Trust & Words related to Mistrust \\
\hline 1 & Honesty & Cheat \\
\hline 2 & Loyalty & Betray \\
\hline 3 & Love & Deception \\
\hline 4 & Confidence & Steal \\
\hline 5 & Assurance & Suspicion \\
\hline 6 & Friendship & Distrust \\
\hline 7 & Security & Sneaky \\
\hline 8 & Integrity & Misleading \\
\hline 9 & Fidelity & Mistrust \\
\hline 10 & Familiarity & Phone \\
\hline 11 & Honor & Beware \\
\hline 12 & Reliability & Harm \\
\hline 13 & Trustworthy & Falsity \\
\hline 14 & Entrust & Lie \\
\hline 15 & Promise & Cruel \\
\hline
\end{tabular}




\section{International Advanced Research Journal in Science, Engineering and Technology}

Vol. 6, Issue 7, July 2019

\begin{tabular}{|c|c|c|c|c|c|c|c|}
\hline \multicolumn{8}{|c|}{ Scales for Trust Using Words } \\
\hline \multicolumn{8}{|c|}{$\begin{array}{l}\text { Below is a survey to evaluate the level of trust for two slideshows, which first slideshow consists } \\
\text { of trust words and second slideshow consists of mistrust words. Please check the level of trust } \\
\text { and mistrust for each session. }\end{array}$} \\
\hline \multicolumn{8}{|c|}{ Question: The first slideshow evokes trust (Note: not at all $=1$, extremely $=7$ ) } \\
\hline & 1 & 2 & 3 & 4 & 5 & 6 & 7 \\
\hline $\begin{array}{c}\text { Slideshow 1: } \\
\text { words relate to } \\
\text { trust }\end{array}$ & & & & & & & \\
\hline \multicolumn{8}{|c|}{ Question: The second slideshow evokes mistrust (Note: not at all $=1$, extremely $=7$ ) } \\
\hline & 1 & 2 & 3 & 4 & 5 & 6 & 7 \\
\hline $\begin{array}{l}\text { Slideshow 2: } \\
\text { words relate to } \\
\text { mistrust }\end{array}$ & & & & & & & \\
\hline
\end{tabular}

Fig. 1 Scales for trust between people and automation

C. EEG Recording and Analysis

The EEG data were recorded using the g.HIamp (256 multichannel amplifier), g. GAMMAsys (active electrode system with g. GAMMAcap) and g. Recorder (brain signal recording software) by g. tec medical engineering company. Per the international 10-20 system of electrode placement, 20 electrodes (Fp1, Fp2, Fpz, F7, F3, Fz, F4, F8, T7, C3, Cz, C4, T8, P7, P3, Pz, P4, T6, O1, O2) were recorded and measured (see Fig. 2). The 10-20 system is based on the relationship between the location of an electrode and the underlying area of the cerebral cortex. The participant's head is fitted with a cap of electrodes (g. GAMMAcap), and the selected 20 electrodes are filled with abrasive electrolyte gel using a syringe. The sampling frequency to record brainwaves is $256 \mathrm{~Hz}$, high-frequency filter as $60 \mathrm{~Hz}$, and low-frequency filter as $0.1 \mathrm{~Hz}[21]$.

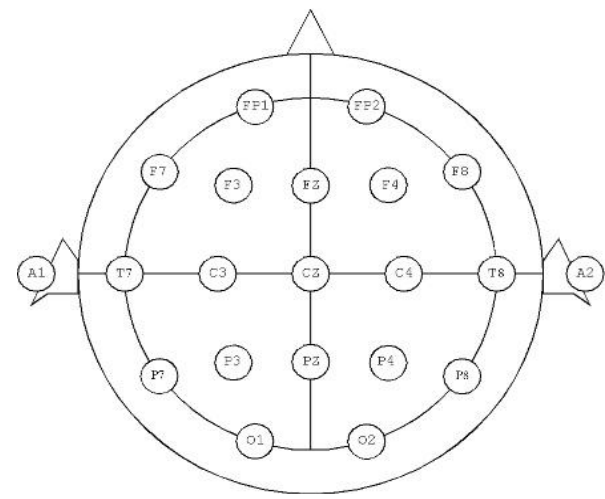

Fig. 2 International 10-20 system for electrode placement (Klem et al., 1999)

\section{ANALYSIS}

The g.Recorder (brain signal recording software) recorded raw EEG data and removed artifacts by using filters. Before an experiment, participants' artifacts such as eye blink, jaw clenching and muscle movement were recorded and marked. After the experiment before analysis, the marked artifacts were removed from raw data using the filters in g.Recorder. This research used power spectrum for identifying specific brainwaves related to trust and mistrust situations. The power spectrum measurement is a common method to quantify EEG raw data to illustrate the distribution of signal power by frequency [22]. To identify specific brainwaves corresponding to the words for trust and mistrust situations, the preprocessed EEG data were analyzed using the power spectrum analysis through the EMSE Suite Data Editor (EEG data editing software) by Cortech Solutions. Power spectrum analysis involved performing a fast Fourier transform (FFT) on defined data intervals. Then, the results were squared and averaged. The power spectrum data are displayed in units of Volts ${ }^{2}$.

\section{RESULT}

Since the 17 participants' brainwaves were normal without any extreme brain activity, the analysis was performed on the averaged data of all the brainwaves. The participants' brainwaves were recorded as they responded to the word selections relative to trust and mistrust by the 10-20 system of electrode placement ( 22 channels) with a total time of 210 seconds for each session. The power spectrum analysis was used to analyze the raw data generated from the 


\section{International Advanced Research Journal in Science, Engineering and Technology}

Vol. 6, Issue 7, July 2019

brainwaves to examine specific brainwaves for the trust and mistrust situations. The researcher used the power spectrum analysis to classify the frequency ranges by brain waves as follows: delta $(\delta, 0.2-4 \mathrm{~Hz})$, theta $(\theta, 4-8 \mathrm{~Hz})$, alpha $(\alpha, 8-13 \mathrm{~Hz})$, beta $(\beta, 13-30 \mathrm{~Hz})$ and gamma $(\gamma, 30-60 \mathrm{~Hz})[23,24]$. Delta and theta waves were not relative to this experiment because delta waves occur in a deep sleep state and theta waves occur during drowsiness; thus, these were not applicable for this experiment. Therefore, the analysis includes the alpha, beta, gamma waves, intra individual and average differences that are compared to the trust and mistrust situations. Further, the individual variability for the brainwaves is high [21], so the analysis includes the intra individual differences, which shows individual difference with baseline and two stimuli of trust and mistrust situation, followed by the average differences.

A. Comparison of Intra individual and Average Differences

According the survey results, the level of trust for the two slideshows relative to trust and mistrust words for the 7 scales, all 17 participants confirmed that Slideshow 1 evoked trust showing an average of 6.64 and Slideshow 2 evoked mistrust showing an average of 6.0 (see Table II). Therefore, this experiment evoked trust and mistrust situation.

Table II Survey Results for the Level of Trust

\begin{tabular}{|l|l|l|l|l|l|l|l|l|}
\hline Question: The first slideshow evokes trust (Note: not at all = 1, extremely $=7$ ) \\
\hline Slideshow 1: words related to trust & & & & & & 16 & 1 & 17 \\
\hline
\end{tabular}

\begin{tabular}{|l|l|l|l|l|l|l|l|l|}
\hline Question: The second slideshow evokes mistrust (Note: not at all = 1, extremely = 7) \\
\hline Slideshow 2: words related to mistrust & 1 & 2 & 3 & 4 & 5 & 6 & 7 & total \\
\hline
\end{tabular}

The frequency of alpha waves ranged from $8 \mathrm{~Hz}$ to $13 \mathrm{~Hz}$. By comparing the intraindividual differences for the trust situations to the baseline (with no stimuli), the power of alpha waves of 16 of 17 participants $(94.11 \%)$ highly increased and the power of 1 participant (P16) (6.25\%) decreased (see Fig. 6). By comparing the intraindividual differences for the mistrust situation to the baseline (with no stimuli), the power of the alpha waves for 5 of 17 participants (P2, P4, P5, P11 and P12) (29.41\%) increased and 12 of 17 participants (70.58\%) decreased (see Fig. 3).

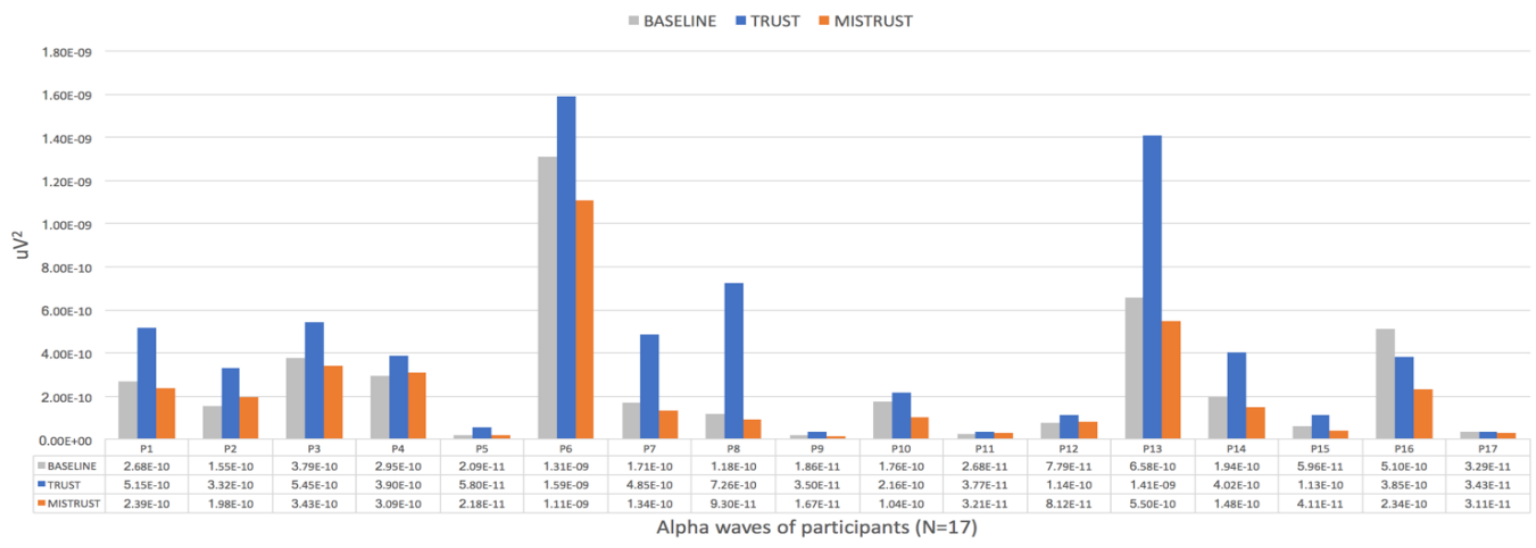

Fig. 3. Comparison of intraindividual differences to the alpha waves

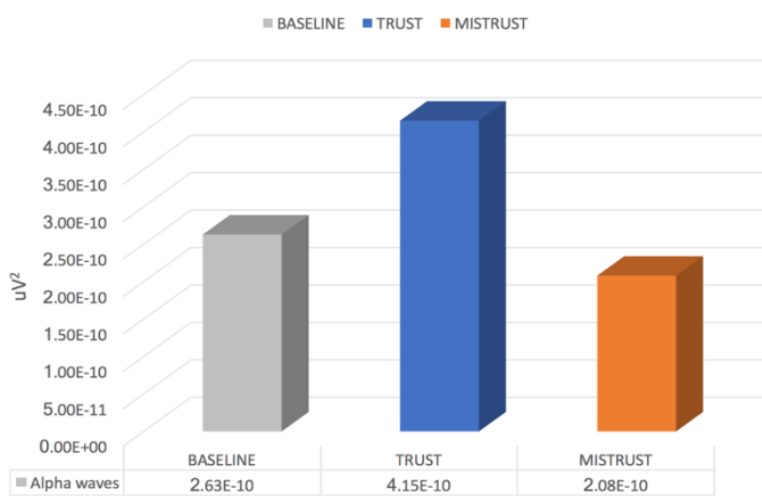

Fig. 4. Comparison of the average differences to the alpha waves 


\section{International Advanced Research Journal in Science, Engineering and Technology}

Vol. 6, Issue 7, July 2019

The averages for the baseline, trust, and mistrust were $2.63 \mathrm{E}-10 u V^{2}, 4.15 \mathrm{E}-10 u V^{2}$ and $2.08 \mathrm{E}-10 u V^{2}$ respectively. By comparing these averages, the power of alpha waves increased for the trust situation with a difference of $1.53 \mathrm{E}-10 \mathrm{uV} \mathrm{V}^{2}$ and decreased for the mistrust situation with a difference of 5.50E-11 uV $\mathrm{V}^{2}$ (see Fig. 4).

The frequency of beta waves ranged from $13 \mathrm{~Hz}$ to $30 \mathrm{~Hz}$. By comparing the intra-individual differences for the trust situation to the baseline (with no stimuli), the power of beta waves for 16 of $17(94.11 \%)$ participants highly increased, but the power of 1 participants (P4) (6.25\%) decreased (see Fig. 8). By comparing the intra-individual differences for the mistrust situation to the baseline (with no stimuli), the power of the beta waves for 11 of 17 (64.70\%) slightly increased, but the power of 6 participants (P2, P7, P12, P15, P16 and P17) (35.29\%) decreased (see Fig. 5).

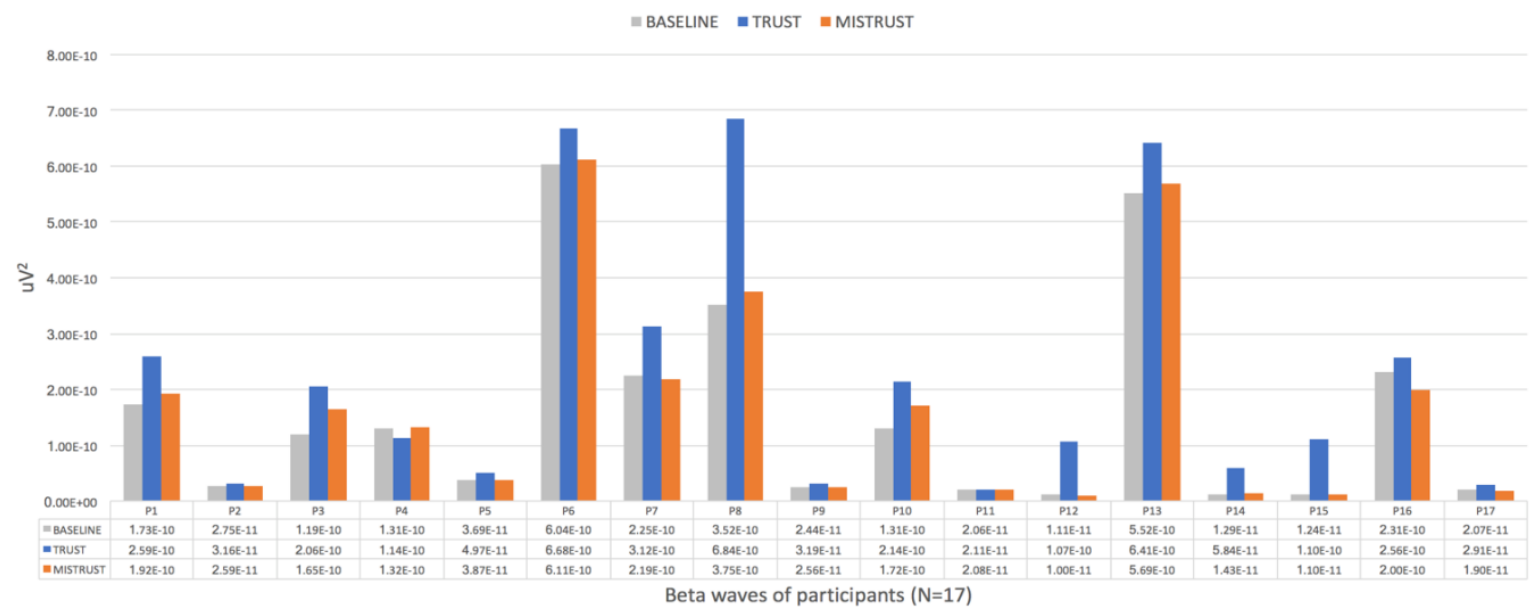

Fig. 5. Comparison of intraindividual differences to the beta waves

The averages of the baseline, trust and mistrust were $1.58 \mathrm{E}-10 u V^{2}, 2.23 \mathrm{E}-10 u V^{2}$ and $1.65 \mathrm{E}-10 u V^{2}$, respectively. A comparison of these averages showed the power of beta waves highly increased for the trust situation to a difference of 6.50E-10 $u V^{2}$ and slightly increased for the mistrust situation to a difference of 7.00E-12 $u V^{2}$ (see Fig. 6).

= BASEUNE $=$ TRUST =MISTRUST

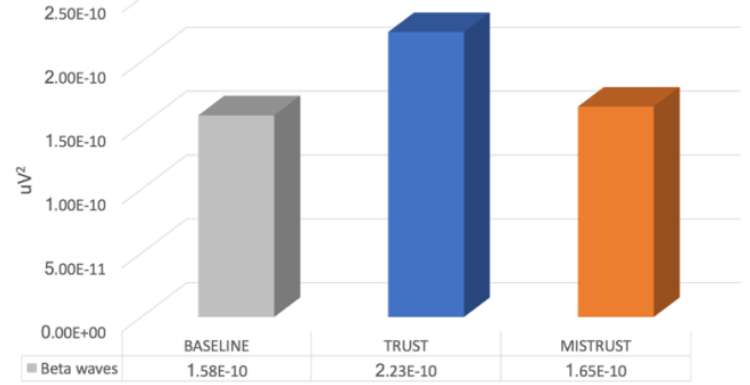

Fig. 6. Comparison of the average differences to the beta waves

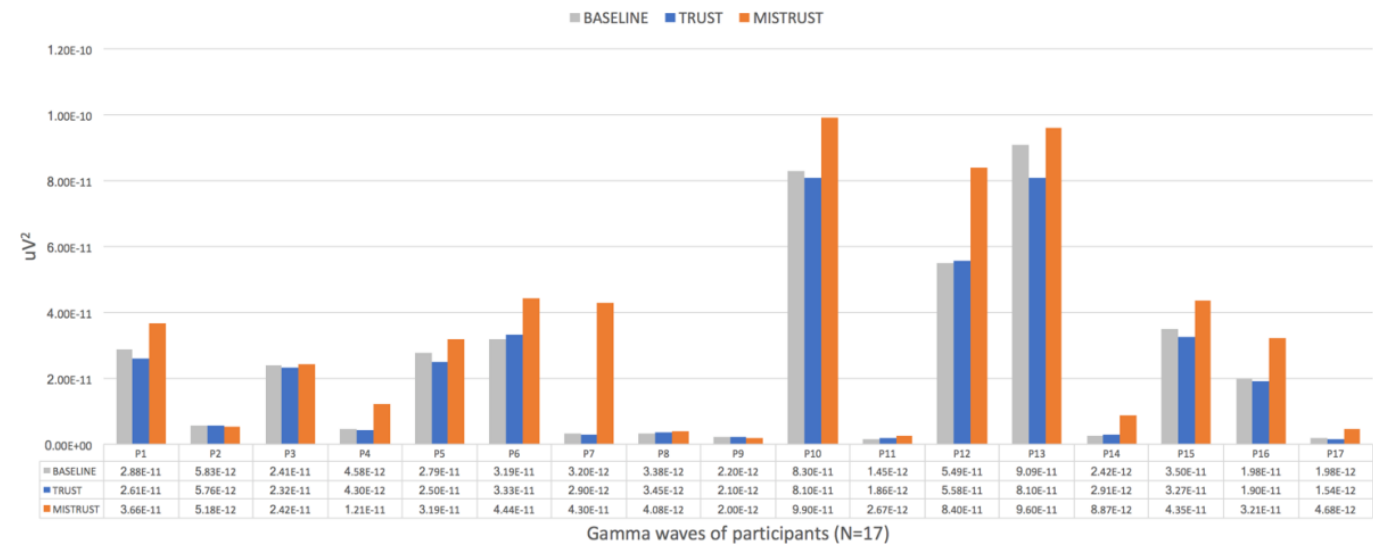

Fig. 7. Comparison of intraindividual differences to the gamma waves 


\section{International Advanced Research Journal in Science, Engineering and Technology}

Vol. 6, Issue 7, July 2019

The frequency of gamma waves ranged from $30 \mathrm{~Hz}$ to $60 \mathrm{~Hz}$. A comparison of the intraindividual differences for the trust situation to the baseline (with no stimuli) showed a slight decrease for the power of gamma waves for 12 of 17 participants (70.58\%), but not in 5 participants (P6, P8, P11, P12 and P14) (29.41\%) (see Fig. 7). A comparison of the intraindividual differences for the mistrust situation to the baseline (with no stimuli) showed a high increase for the power of the gamma waves for 15 of 17 participants (88.23\%), but not in 2 participants (P2 and P9) (11.76\%) (see Fig. 7).

The averages of the baseline, trust, and mistrust were $1.75 \mathrm{E}-09 u V^{2}, 1.68 \mathrm{E}-09 u V^{2}$ and $2.25 \mathrm{E}-09 u V^{2}$, respectively. A comparison of these averages showed a slight decrease for the power of gamma waves for the trust situation with a difference of $7.00 \mathrm{E}-11 \mathrm{uV}^{2}$ and showed a high increase for the mistrust situation with a difference of $5.00 \mathrm{E}-10 \mathrm{uV} \mathrm{V}^{2}$ (see Fig. 8).

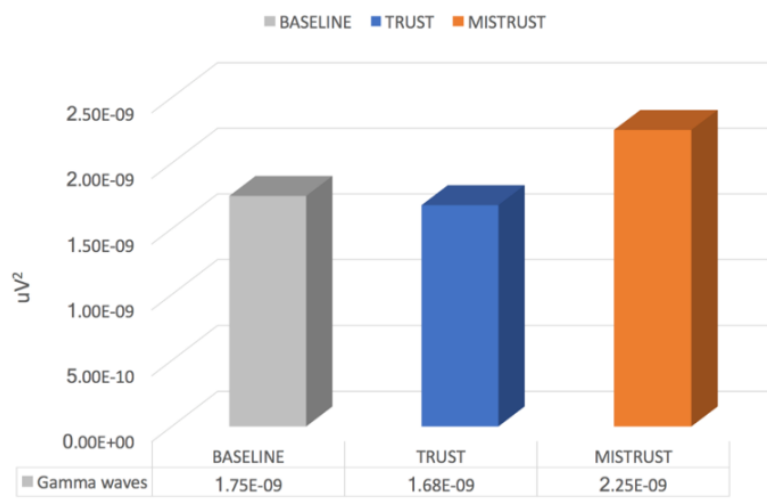

Fig. 8. Comparison of average differences of the gamma waves

B. Comparison of Trust and Mistrust Differences

By comparing the alpha waves, beta waves and gamma waves in the trust and mistrust situation, the alpha and beta waves are associated with the trust situation and the gamma waves are associated with the mistrust situation, so they need to analyze with more details. By comparing the trust differences to the alpha waves when the baseline is $0,94.11 \%$ of participants increases in the trust situation and the standard deviation is 2.25E-10 (see Fig. 9).

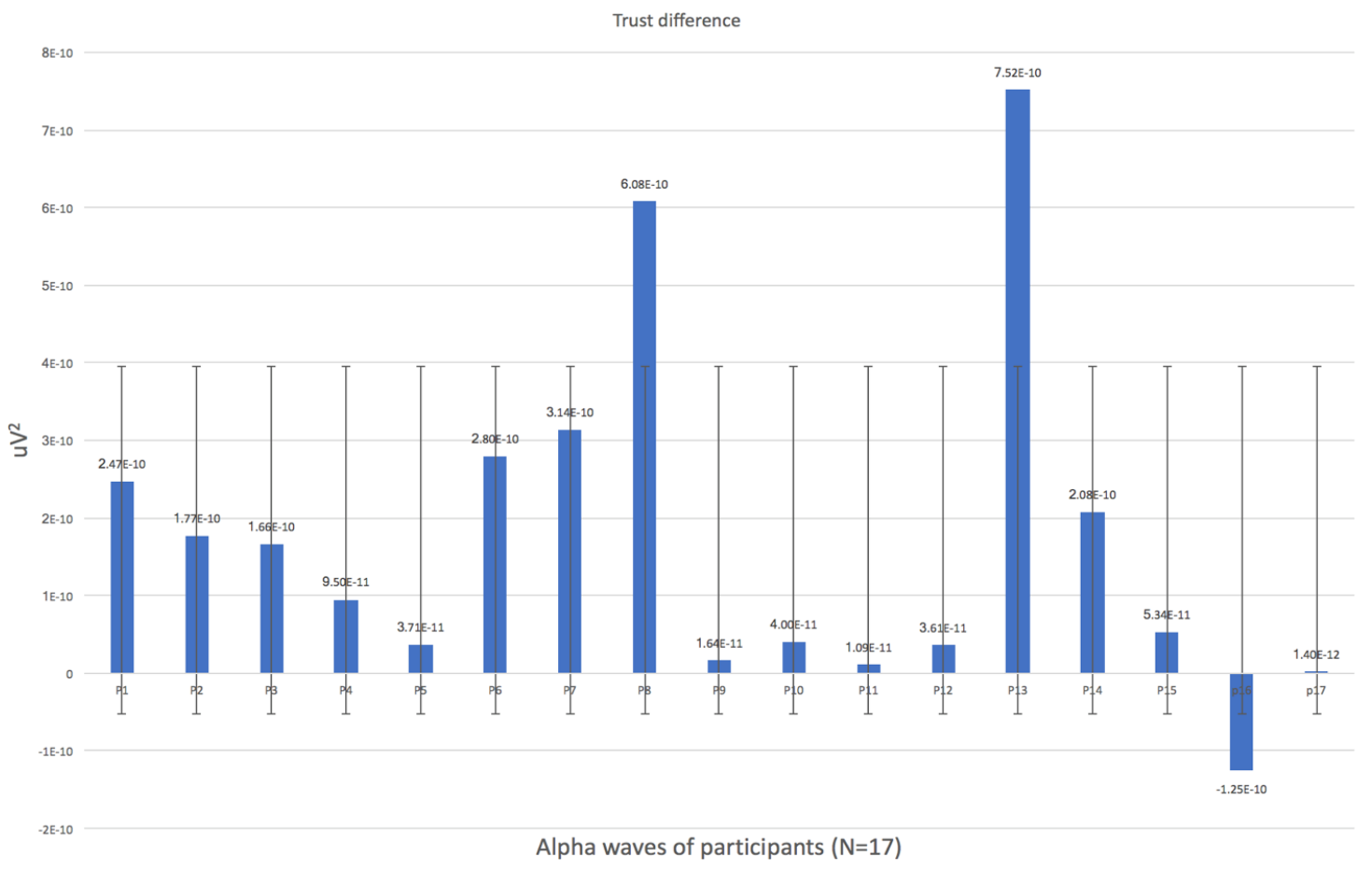

Fig. 9. Comparison of trust differences to the alpha waves

By comparing the trust differences to the beta waves when the baseline is $0,94.11 \%$ of participants increases in the trust situation and the standard deviation is 7.96E-10) (See Fig. 10). 


\section{International Advanced Research Journal in Science, Engineering and Technology}

Vol. 6, Issue 7, July 2019

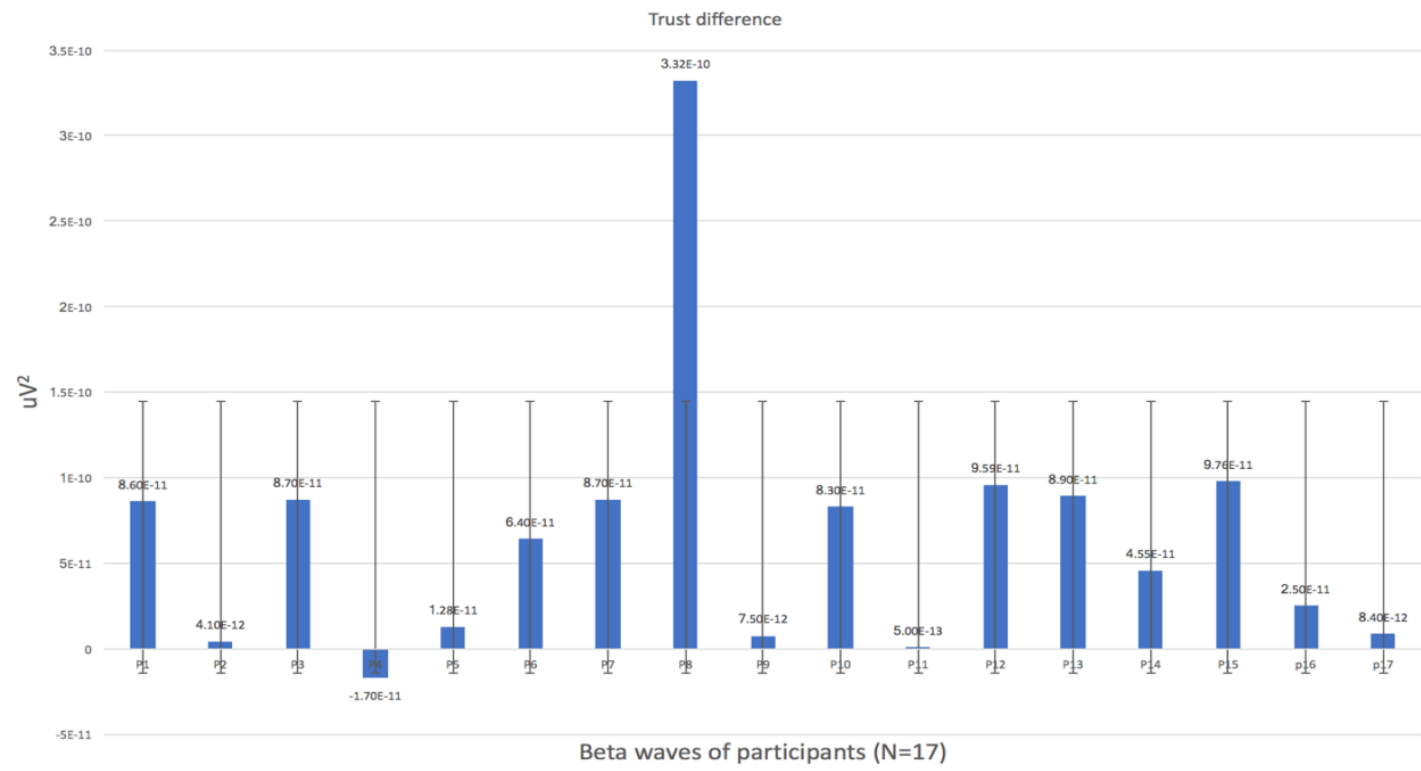

Fig. 10. Comparison of trust differences to the beta waves

By comparing the mistrust differences to the gamma waves when the baseline is $0,88.23 \%$ of participants increases in the mistrust situation and the standard deviation is 1.09E-11) (See Fig. 11).

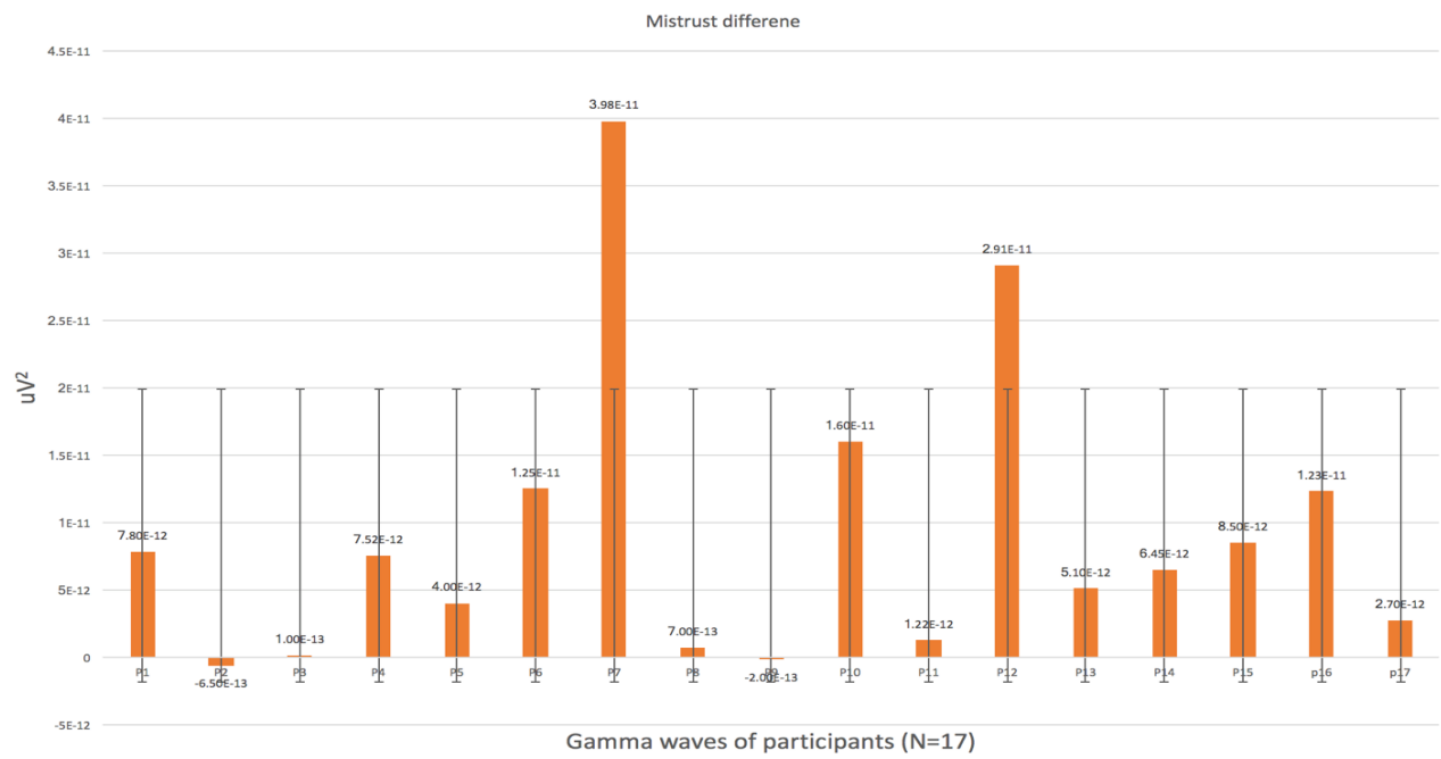

Fig. 11. Comparison of mistrust differences to the gamma waves

\section{CONCLUSIONS AND DISCUSSION}

Based on the power spectrum analysis, a comparison of trust and mistrust situations by $\alpha, \beta$, and $\gamma$ waves is shown. While alpha and beta waves were stronger in the trust situations, gamma waves were stronger in the mistrust situations (see Fig. 3-11). Alpha waves represent a calm state without any stress or tension [25]. These waves relate to recalling memory, relieving pain and reducing stress and anxiety [26,27,28,29]. Beta waves correspond cognitive tasks such as attention, problem-solving, judgment, and decision-making [30]. In contrast, gamma waves are the fastest waves that are indicative of anxiety and processes advanced cognitive information such as reasoning and judgement [31]. Gamma waves are highly related to social anxiety, which was increased during the speech anticipation condition [32]. By examining alpha, beta and gamma waves, trust situations can help calm down or execute normal cognitive tasks. However, mistrust situations can interrupt mental activity because of increased stress and anxiety.

As denoted by the findings of this research, trust can assist in effective decision-making by increasing concentration and performance. However, mistrust can impede the effectiveness of decision-making by increasing stress and anxiety. 


\section{International Advanced Research Journal in Science, Engineering and Technology}

Vol. 6, Issue 7, July 2019

This research presents the differences between specific brainwaves, in response to the words related with trust and mistrust. Further research with more samples of brainwaves will aid in further investigation of complex cognitive processes between trust and mistrust; eventually, to define how trust can affect performance and decision-making.

\section{REFERENCES}

[1]. M. Deutsch. The resolution of conflict: Constructive and destructive processes. Yale University Press, 1977.

[2]. J. Scanzoni. Social exchange and behavioral interdependence. In Social exchange in developing relationships, 1979, 61-98.

[3]. J. B. Rotter, J. B. Interpersonal trust, trustworthiness, and gullibility. American Psychologist, 35, 1980, 1-7.

[4]. J.K. Rempel, J. G. Holmes, and M.P. Zanna. Trust in close relationships. Journal of Personality and Social Psychology, 49, 1985 , 95-112.

[5]. J. K. Rempel, and J. G. Holmes. How do I trust thee, Psychology today, 20(2), 1980, 28-34.

[6]. B. Barber. The Logic and Limits of Trust. New Brunswick. Rutgers University Press, 1983.

[7]. B.M.Muir. Trust b/w human \& machine, \& the design of decision aid. International Journal of Man-Machine Studies, 27(5-6), 1987, 527-539.

[8]. R.Bhattacharya, T.M.Devinney, \& M.M.Pillutla. A formal model of trust based on outcome. Academy of management review, 23(3), 1998, 459-472.

[9]. R.C.Mayer, J.H.Davis, \& F. D. Schoorman. An integrative model of organizational trust. Academy of Management Review, $20,1995,709-734$.

[10]. F. J. Lerch, and M. J. Prictula. How do we trust machine advice? In Proceedings of the third international conference on human-computer interaction on Designing and using human-computer interfaces and knowledge based systems, 2nd ed, 1989, 410-419.

[11]. J. D. Lee, and K. A. See. Trust in technology: Designing for appropriate reliance. Human Factors, 46, $2004,50-80$.

[12]. I. L. Singh, R. Molloy, and R. Parasuraman. Automation-induced "complacency": Development of the Complacency-Potential Rating Scale. The International Journal of Aviation Psychology, 3(2), 1993, 111-122.

[13]. J.D.Lee, \& N.Moray. Trust, self-confidence, \& operators' adaptation to automation. International Jour of Human-Computer Studies, 40, 1994, $153-184$.

[14]. B. M. Muir, and N. Moray. Trust in automation: Part U. Experimental studies of trust and human intervention in a process control simulation. Ergonomics, 39(3), 1996, 429-460.

[15]. J. S. Winston, B. A. Strange, J. O'Doherty, and R. J. Dolan. Automatic and intentional brain responses during evaluation of trustworthiness of faces. Nature neuroscience, 5(3), 2002, 277.

[16]. F. Krueger, K. McCabe, J. Moll, N. Kriegeskorte, R. Zahn, M. Strenziok, ... and J. Grafman. Neural correlates of trust. Proceedings of the National Academy of Sciences, 104(50), 2004, 20084-20089.

[17]. A. Dimoka. Brain mapping of psychological processes with psychometric scales: An fMRI method for social neuroscience. NeuroImage, 54, 2011, S263-S271.

[18]. A. Dimoka. What does the brain tell us about trust and distrust? Evidence from a functional neuroimaging study. Mis Quarterly, $2010,373-396$.

[19]. J. Y. Jian, A. Bisantz, and C. G. Drury. Foundations for an Empirically Determined Scale of Trust in Automated Systems. International journal of cognitive ergonomics, 4(1), 2000, 53-71.

[20]. A.Bisantz, J.Llinas, Y.Seong, Y, R.Finger, \& J.Y. Jian. Empirical Investigations of Trust-Related Systems Vulnerabilities in Aided, Adversarial Decision Making. STATE UNIV OF NEW YORK AT BUFFALO CENTER OF MULTISOURCE INFORMATION FUSION, 2000.

[21]. J. A. Meltzer, H. P. Zaveri, I. I. Goncharova, M. M. Distasio, X. Papademetris, S. S. Spencer, ... and R. T. Constable. Effects of working memory load on oscillatory power in human intracranial EEG. Cerebral Cortex, 18(8), 2007. 1843-1855.

[22]. M.Teplan, A.Krakovska, \& S.Stolc. EEG responses to long-term audio-visual stimulation. International Jour of Psycho, 59(2), 2006, 81-90.

[23]. S. Sanei, and J. A. Chambers. EEG signal processing. John Wiley \& Sons Ltd, 2007.

[24]. G. Pfurtscheller, and \& F. L. Da Silva. Event-related EEG/MEG synchronization and desynchronization: basic principles. Clinical neurophysiology, 110(11), 1999, 1842-1857.

[25]. A. Ashtaputre-Sisode. Emotions and Brainwaves. The international Journal of Indian Psychology, 3(5), 2016.

[26]. J. Williams, D. Ramaswamy, and A. Oulhaj. $10 \mathrm{~Hz}$ flicker improves recognition memory in older people. BMC Neurosci, 7, $2006,21$.

[27]. J.H. Williams. Frequency specific effects of flicker on recognition memory. Neuroscience, 104(2), 2001, 283-286

[28]. T. Nomura, K. Higuchi, H. Yu, S. I. SASAKI, S. Kimura, H. Itoh, ... and K. Kawai. Slow-wave photic stimulation relieves patient discomfort during esophagogastroduodenoscopy. Journal of gastroenterology and hepatology, 21(1), 2006, 54-58.

[29]. H. C. Ossebaard. Stress reduction by technology? An experimental study into the effects of brain machines on burnout and state anxiety. Appl Psychophysiol Biofeedback, 25(2), 2000, 93-101.

[30]. P. N. Friel. EEG biofeedback in the treatment of attention deficit/hyperactivity disorder. Alternative medicine review, 12(2), 2007,146.

[31]. B. E. Canan, S. Daniel, S. Martin, S. Michael, and B. Erol. Gamma-band responses in the brain: a short review of psychophysiological correlates and functional significance International Journal of Psychophysiology, 24(1-2), 1996, 101-112

[32]. V. Miskovic, A. R. Ashbaugh, D. L. Santesso, R. E. McCabe, M. M. Antony, and L. A. Schmidt. Frontal brain oscillations and social anxiety: A cross-frequency spectral analysis during baseline and speech anticipation Biological psychology, 83(2), 2009, 125-32.

\section{BIOGRAPHIES}

Dr. Seeung Oh is an Adjunct Professor in the department of Applied Engineering Technology at North Carolina Agricultural and Technical State University, Greensboro, USA. He earned PhD in Industrial and Systems Engineering at North Carolina Agricultural and Technical State University in 2018. Dr. Oh's research interests include human factors and ergonomics design with neurological technologies, human trust in automated systems, decision-making and brain-computer interface (BCI) and user interface(UI) design and information visualization.

Dr. Younho Seong is an Associate Professor in the department of Industrial and Systems Engineering at North Carolina Agricultural and Technical State University, Greensboro, USA. He earned PhD in Industrial Engineering from The State University of New York at Buffalo in 2000. Dr. Seong's research interests include judgment and decision making, human trust in automation, human computer interface, data visualization, neuroergonomics, brain computer interface. 